\title{
Article \\ In Situ Neutron Radiography Investigations of Hydrogen Related Processes in Zirconium Alloys
}

\author{
Mirco Grosse ${ }^{1, *(\mathbb{D}}$, Burkhardt Schillinger ${ }^{2}$ and Anders Kaestner ${ }^{3}$ (D) \\ 1 Karlsruhe Institute of Technology, Institute for Applied Materials, P.O. Box 3640, 76021 Karlsruhe, Germany \\ 2 FRM II and Physik-Department E21, Technische Universität München, 85748 Garching, Germany; \\ burkhard.schillinger@frm2.tum.de \\ 3 Laboratory for Neutron Scattering and Imaging, Paul Scherrer Institut, 5232 Villigen PSI, Switzerland; \\ anders.kaestner@psi.ch \\ * Correspondence: mirco.grosse@kit.edu
}

Citation: Grosse, M.; Schillinger, B.; Kaestner, A. In Situ Neutron

Radiography Investigations of Hydrogen Related Processes in Zirconium Alloys. Appl. Sci. 2021, 11, 5775. https://doi.org/10.3390/ app11135775

Academic Editors: Wolfgang Treimer and Stanislaw M. Dubiel.

Received: 17 May 2021

Accepted: 15 June 2021

Published: 22 June 2021

Publisher's Note: MDPI stays neutral with regard to jurisdictional claims in published maps and institutional affiliations.

Copyright: (c) 2021 by the authors. Licensee MDPI, Basel, Switzerland. This article is an open access article distributed under the terms and conditions of the Creative Commons Attribution (CC BY) license (https:// creativecommons.org/licenses/by/ $4.0 /)$.
Featured Application: The investigations provide information about important parameters needed for the modelling of design bases, and beyond design bases, nuclear accidents and processes occurring during the long-term dry storage of spent nuclear fuel.

Abstract: In situ neutron radiography experiments can provide information about diffusive processes and the kinetics of chemical reactions. The paper discusses requirements for such investigations. As examples of the zirconium alloy Zircaloy-4, the hydrogen diffusion, the hydrogen uptake during high-temperature oxidation in steam, and the reaction in nitrogen/steam and air/steam atmospheres, results of in situ neutron radiography investigations are reviewed, and their benefit is discussed.

Keywords: zirconium alloy; hydrogen diffusion; hydrogen uptake; high-temperature oxidation

\section{Introduction}

Hydrogen in metals is an evergreen in material research. Even small amounts of hydrogen absorbed in a material can degrade the mechanical properties significantly. Several fracture mechanisms caused by hydrogen are well known. One example is the so-called fisheye fracture occurring in steels even with hydrogen concentrations in the order of magnitude of a few wt.ppm. Here, dissolved hydrogen (protons) moves to the crotches of grain boundaries, recombines with molecular hydrogen, and builds up an inner pressure, which can exceed the fracture strength even with subcritical external load.

Hydrogen pickup degrades the mechanical properties of zirconium alloys used for nuclear fuel claddings too. Hydrogen is absorbed by water corrosion during operation or by high-temperature steam oxidation under accident conditions.

The hydrogen concentration in spent fuel claddings has values between 50 and 80 wt.ppm depending on the chemical composition and the production paths of the tubes [1]. At high burn-up, concentrations of up to $650 \mathrm{wt} . \mathrm{ppm}$ can be reached. The solubility of hydrogen in Zircaloy-4 ( $\mathrm{Zr} 1.3 \% \mathrm{Sn})$ at a reactor operation temperature of $300{ }^{\circ} \mathrm{C}$ is about 70 wt.ppm [2]. Most of the hydrogen is dissolved in the zirconium lattice during operational conditions up to a burn-up of about $50 \mathrm{GWd} / \mathrm{MTU}$. For discharging of the fuel assemblies, the reactor is cooled down. The hydrogen solubility at room temperature is very low. Hydrides precipitate nearly exclusively with orientation on a circumferential direction because the outer pressure is higher than the inner pressure in the fuel rods (see Figure 1). After storage in a spent fuel pool at temperatures of about $60^{\circ} \mathrm{C}$, the fuel rods heat up to temperatures between 350 and $400{ }^{\circ} \mathrm{C}$ at the beginning of the dry storage due to the remaining decay heat. Most of the hydrides become dissolved again (hydrogen solubility at $400{ }^{\circ} \mathrm{C}$ is about $200 \mathrm{wt}$.ppm). The decrease in decay heat results in a very slow cool-down of the spent fuel rods, and with it to a reprecipitation of the hydrides. Because 
the inner pressure in the rods is higher than the outer pressure under dry storage conditions, the hydrides can be oriented in a radial direction. This orientation degrades the mechanical strength much stronger than hydrides oriented in a circumferential direction. In order to develop models describing these processes over a time scale of 50 to 100 years, the influence of system parameters such as temperature, texture, grain size, chemical composition, and elastic strain on the hydrogen diffusivity and solubility has to be determined accurately.

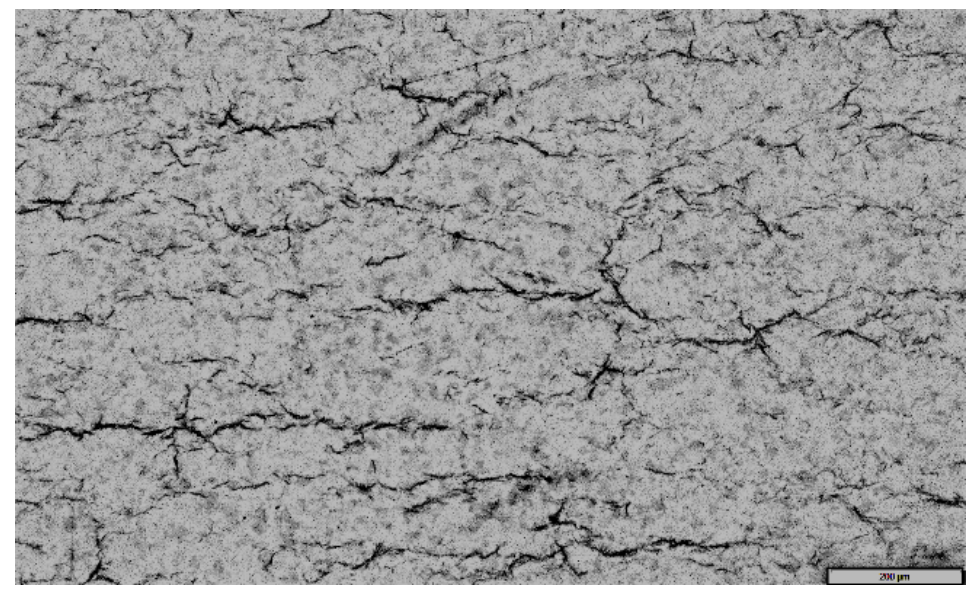

Figure 1. Circumferential hydrides (dark) in Zircaloy-4.

During design basis large break loss of coolant accidents (LB-LOCAs), band-shaped hydrogen enrichments with concentrations of several hundred wt.ppm can be formed due to the so-called secondary hydrogen uptake via the inner surface of the cladding tubes after failure. Hydrogen concentrations of up to more than 3500 wt.ppm were detected in cladding tubes applied in large-scale severe accident simulation tests. Figure 2 shows the distribution of these high hydrogen concentrations. It results in an embrittlement of the materials as it was shown in [3]. The sample fails in the tensile test at the hydrogen enrichments if the local hydrogen concentration exceeds $1500 \mathrm{wt} . \mathrm{ppm}$. This material degradation provides the risk of brittle thermo-shock fracture during emergency cooling, terminating the accident. If this happens, fuel and fission products could be released and placed on the bottom of the reactor vessel, resulting in coolability issues. Therefore, one focus of the actual nuclear reactor safety research is the investigation of the concentration, shape, and dimension of the hydrogen enrichments after several accident scenarios.

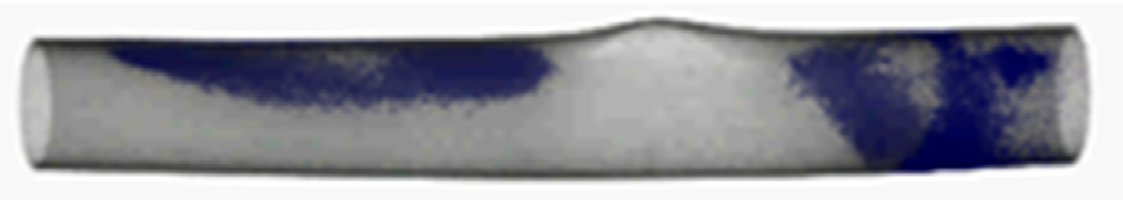

Figure 2. Hydrogen distribution in the cladding around the burst opening of rod \#04 of the QUENCHL3 test (the positions containing hydrogen are marked with blue color).

Neutron imaging is a powerful tool for the investigation of hydrogen in zirconium alloys because the macroscopic total neutron cross section of hydrides can be up to $2500 \%$ compared with one of the typical zirconium alloys applied as cladding material. Several groups worldwide applied neutron imaging for such investigations during the last years [4-14]. However, only few investigations were performed in situ. Often, such in situ investigations are very helpful to understand the dynamic of physicochemical processes.

This paper discusses the requirements for in situ neutron radiography investigations and shows the benefits of such investigations in examples of the hydrogen absorption, diffusion, and redistribution in nuclear fuel claddings made of zirconium alloys. 


\section{Experimental Requirements}

In situ neutron radiography investigations of hydrogen-related processes occurring at temperatures between 250 and $1400{ }^{\circ} \mathrm{C}$ combine the requirements of laboratory reaction furnaces:

- Well-controlled temperature protocol and homogeneous temperature fields;

- Well-defined and changeable gas atmosphere and nonreactive furnace structures and sample holders with the general needs of neutron radiography;

- High transmission by less material in the beam;

- The material of the sample environment in the beam should be distributed homogeneously to have as few as possible additional structures in the images;

- Short distance between sample and detector to increase the spatial resolution even at lower L/D;

- $\quad$ No overheating of the detector system by the in situ furnace;

- Low-activation materials, long-term activated components should be easily replaceable.

Particularly, internal structures of the sample environment can change their position by thermal expansion, changing of sample's weight, or deformation. Such effects make referencing difficult or impossible. Even position changes smaller than the pixel size become visible. For instance, it is very difficult to reference a high-temperature image by using an image taken at room temperature. If possible, the reference image should be taken under the same conditions as the images to be referenced.

In addition to high-temperature chambers available at the neutron source sites, some user-dedicated devices exist [11,14]. In the following, the INRRO (in situ neutron radiography reaction oven) furnace of KIT [15] is introduced. Figure 3 gives a scheme of this high-temperature chamber. In Figure 4, pictures of the furnace mounted at ANTARES and a radiograph of the empty furnace are shown. The furnace can be applied for experiments between room temperature and $1500{ }^{\circ} \mathrm{C}$. The INRRO consists of a water-cooled doublewalled steel container with non-water-cooled flanges at opposite sides as beam windows. Inside the container is a $\mathrm{ZrO}_{2}$ fiber thermal insulation and the furnace tube made of $\mathrm{Al}_{2} \mathrm{O}_{3}$ heated by a niobium wire. Argon purges this part of the furnace. Thermocouples are installed between the heating wires and the furnace tube. The electric power is controlled on the basis of one of the thermocouples by an Eurotherm controller. The composition of the gas flowing through the furnace tube is defined by a Bronkhorst system consisting of two gas flow controllers (one for argon, the other one for an additional gas, such as $\mathrm{H}_{2}, \mathrm{O}_{2}$, or $\mathrm{N}_{2}$ ), a mass flow controller for water, and an evaporator and mixer (CEM). The sample can be mounted on a sample holder rod in an airlock. This allows keeping the furnace at temperature and moving the sample in and out of the furnace without longsome heat-up or cool-down.

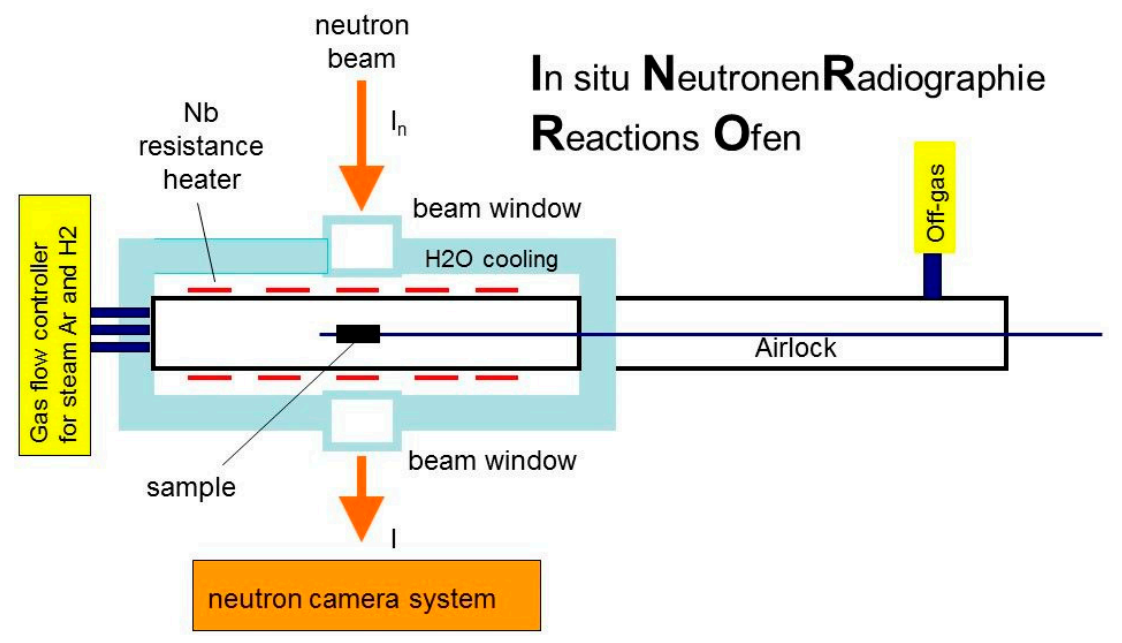

Figure 3. Scheme of the INRRO (in situ neutron radiography reaction oven) furnace of KIT. 

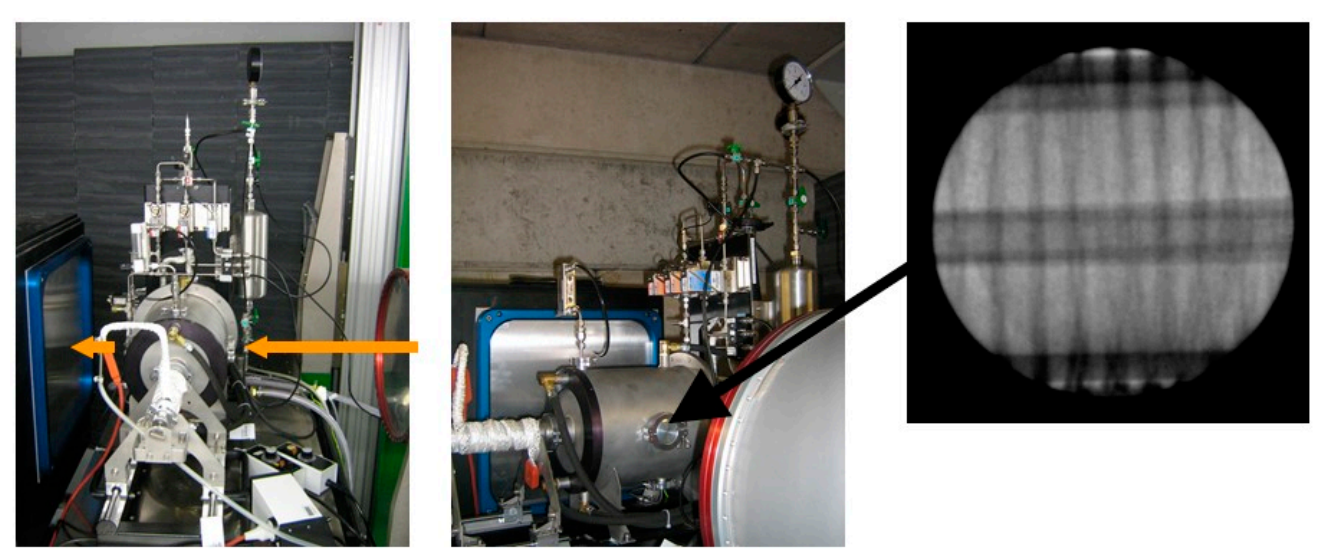

Figure 4. The INRRO furnace mounted at the ICON beamline and a radiograph of the empty furnace.

Another example is a special sample holder for in situ tensile tests at a defined temperature in the range of room temperature to $450{ }^{\circ} \mathrm{C}$ to study the hydrogen redistribution in stressed and precracked pressure tube samples constructed by CNEA, Buenos Aires, Argentina (see Figure 5). This sample holder can be mounted at a load machine and heat a sample to the test temperature. The first in situ tests with this sample holder were already performed at ANTARES, FRM II. The data analysis is still in progress, and the results are not yet published.

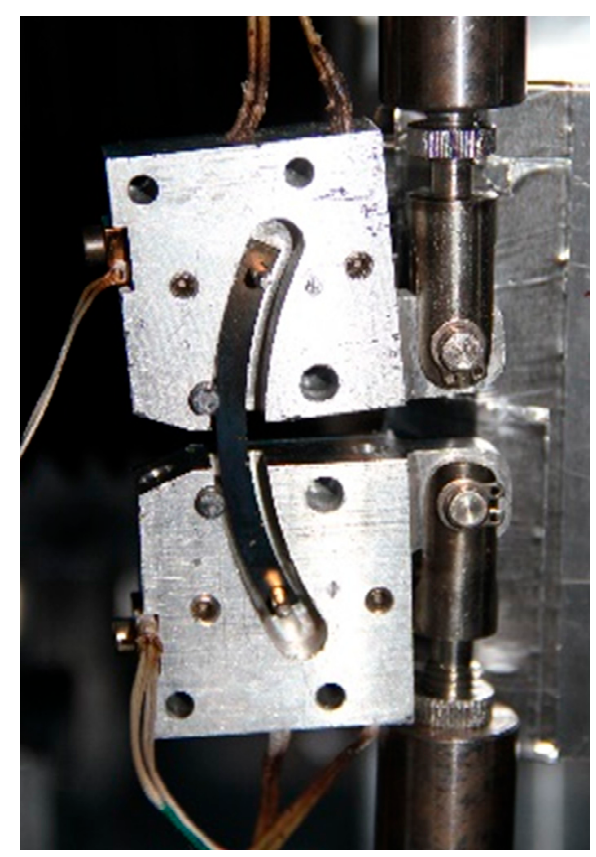

Figure 5. Sample holder constructed by CNEA, Buenos Aires, for a mechanical load machine to perform tensile tests at higher temperatures.

\section{Examples of In Situ Neutron Radiography Investigations}

In this section, three examples of in situ investigations of the hydrogen behavior in nuclear fuel cladding materials are given. First, in situ measurements of the hydrogen diffusion into a solid cylinder made of the zirconium alloy Zircaloy-4 (Zry-4) were described, followed by investigations of the hydrogen uptake of cladding tube segments made of Zry-4 during steam oxidation and during oxidation in various nitrogen-containing atmospheres. In all in situ experiments, LiF scintillators were applied. 


\subsection{Hydrogen Diffusion at Temperatures between 900 and $1400{ }^{\circ} \mathrm{C}$}

The aim of these investigations was the determination of the temperature correlation of the diffusivity of hydrogen in Zircaloy- 4 in the high-temperature $\beta$ phase. In the literature, two different correlations are given for this zirconium phase $[16,17]$ determined for different temperature ranges.

\subsubsection{Material and Measurements}

The measurements of the hydrogen diffusion in Zry-4 (Zr, $1.5 \% \mathrm{Sn}, 0.21 \% \mathrm{Fe}, 0.10 \%$ $\mathrm{Cr}$ ) were performed using solid cylinders made of this material. The diameter was $12 \mathrm{~mm}$, the height $20 \mathrm{~mm}$. These cylinders were oxidized for $30 \mathrm{~min}$ at $1200^{\circ} \mathrm{C}$ in an argon/oxygen atmosphere, producing an approximately $120 \mu \mathrm{m}$ thick oxide layer, which prevents hydrogen pickup. The oxide scale was removed at one base plane of the cylinder by mechanical grinding and polishing to allow hydrogen penetrating into the sample through this plane.

The in situ neutron radiography investigations were performed at the ICON facility at SINQ (Paul Scherrer Institut, Villigen, Switzerland) at temperatures of 900, 1000, 1100, 1200, and $1300{ }^{\circ} \mathrm{C}$. The furnace was mounted at the table for large samples. A collimation of about 600 in terms of $\mathrm{L} / \mathrm{D}$ was applied. The thermal neutron flux at this beamline position was $3.9 \times 10^{6} \mathrm{n} \mathrm{cm}^{-2} \mathrm{~s}^{-1}$. The illumination time per image was $19 \mathrm{~s}$. Together with the readout time, this resulted in a frame repetition rate of $0.05 \mathrm{~Hz}$. The pixels had a size of about $58 \mu \mathrm{m}$, and the field of view was $464 \mathrm{~mm} \times 464 \mathrm{~mm}$.

The annealings were performed in a flowing argon atmosphere $(50 \mathrm{~L} / \mathrm{h})$. After the collection of images for the initial state during the first $3 \mathrm{~min}$, a hydrogen injection of $8 \mathrm{~L} / \mathrm{h}$ into the flowing gaseous atmosphere was started. The images were referenced to the first images taken at the test temperature before the hydrogen injection was started. The resulting images show only the changes in the sample transmission to the initial state. This means that only the hydrogen distribution in the sample is displayed.

\subsubsection{Results}

Figure 6 gives examples of the images taken at $900{ }^{\circ} \mathrm{C}$ at various times after starting the hydrogen injection into the furnace. A video about this process is available online as supplement S1. The progress of the hydrogen penetration into the solid cylinder is clearly visible.

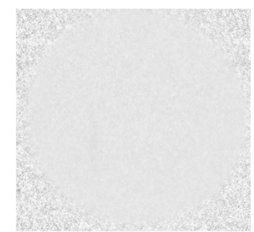

$0 \mathrm{~s}$

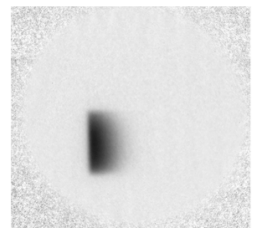

$600 \mathrm{~s}$

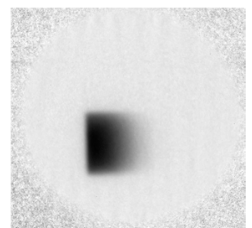

$1200 \mathrm{~s}$

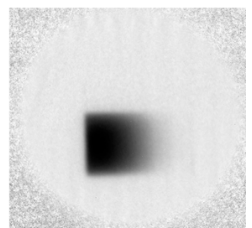

$1800 \mathrm{~s}$

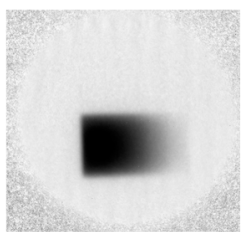

$2400 \mathrm{~s}$

Figure 6. Image sequence of the hydrogen diffusion into Zry-4 at $1173 \mathrm{~K}$.

The transmission distribution can be determined for each image. The macroscopic total neutron cross section was calculated from these transmissions. As an example, Figure 7a plots these distributions for several times of the test at $1200^{\circ} \mathrm{C}$. These curves were fitted by the solution of Fick's law for constant concentration at the surface through which the hydrogen penetrates.

$$
c(x, t)=c_{0}\left(1-\operatorname{erf}\left(\frac{x}{2 \sqrt{D t}}\right)\right)
$$




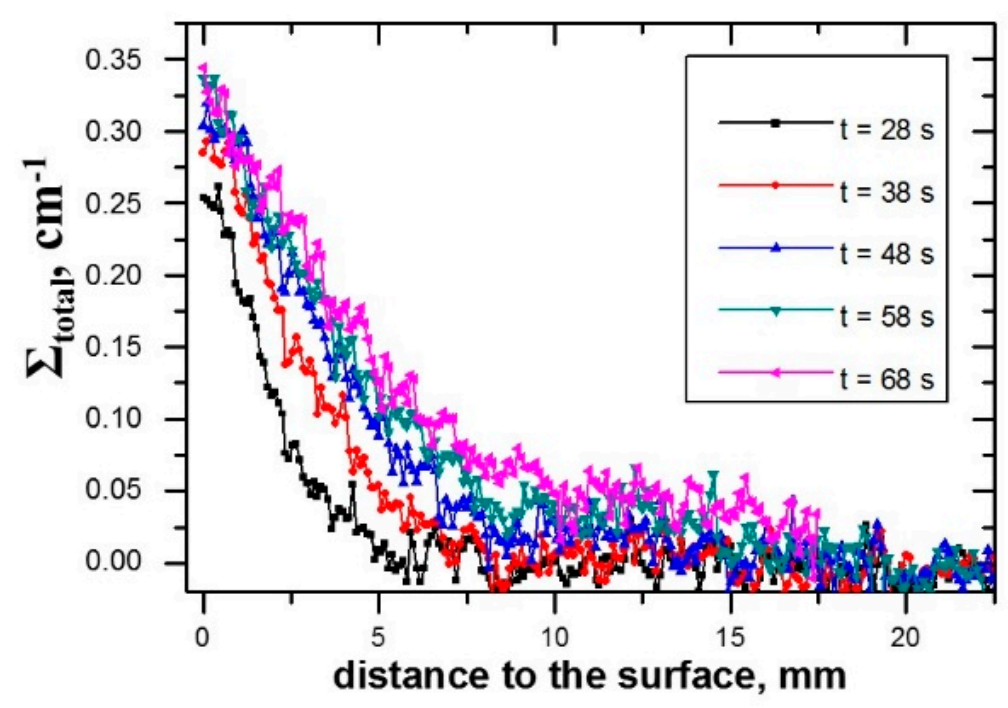

(a)

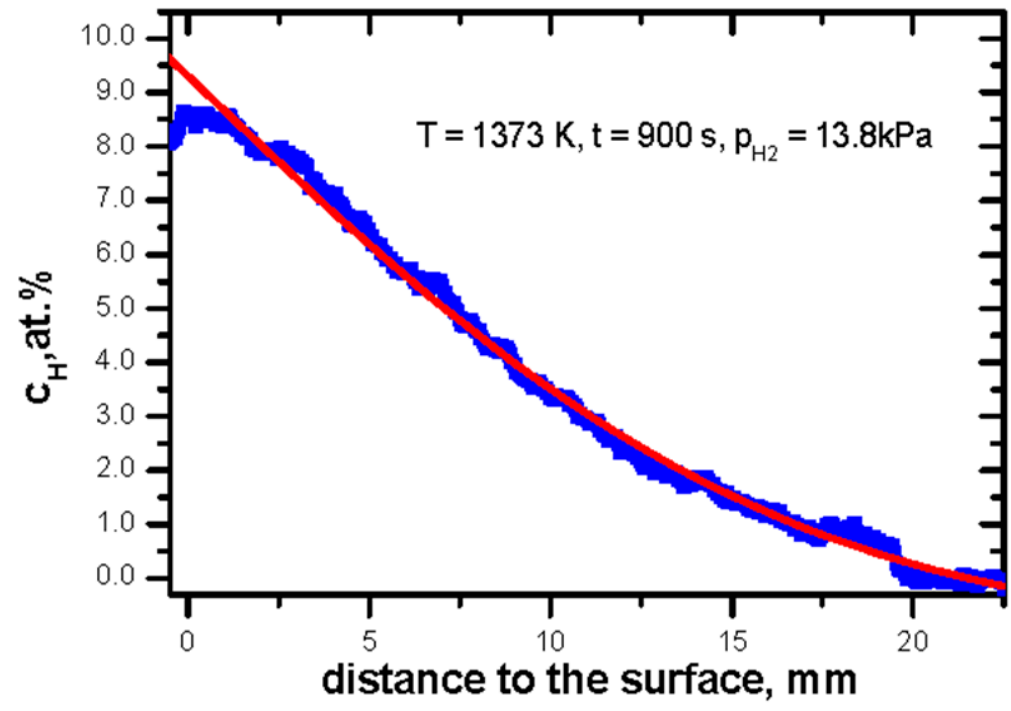

(b)

Figure 7. (a) Dependence of the total neutron cross section on the distance to the surface where the hydrogen penetrates at $1200^{\circ} \mathrm{C}$ for annealing times between 28 and $68 \mathrm{~s}$ and (b) fit of the measured diffusion hydrogen distribution after 15 min annealing at $1100{ }^{\circ} \mathrm{C}$ with Equation (1).

$c(x, t)$ is the actual concentration, $c_{0}$ the constant concentration at the surface, $x$ the distance to the surface, $D$ the diffusivity, and $t$ the time. This equation is valid as long as the hydrogen does not reach the opposite end of the sample. Because the total macroscopic neutron cross section depends linearly on the number density of hydrogen, no calibration of this dependence is needed to determine the diffusivity from the width of the distribution given by $\operatorname{erf}\left(\frac{x}{2 \sqrt{D t}}\right)$. An example for the fits is given in Figure $7 \mathrm{~b}$.

\subsubsection{Discussion}

The temperature dependence of the determined diffusivity is given in an Arrhenius plot in Figure 8, together with temperature correlations calculated from correlations given in the literature [15-17]. The length of the lines gives the temperature range used for the 
determination of the correlations. The values determined here agree at temperatures of 1100 and $1200{ }^{\circ} \mathrm{C}$ with the correlation given by Someno [16], but at 900 and $1000{ }^{\circ} \mathrm{C}$ with the one published by Gelezunas [17]. It looks like the different limited temperature ranges of the two investigations are the reason for the difference in the temperature correlation.

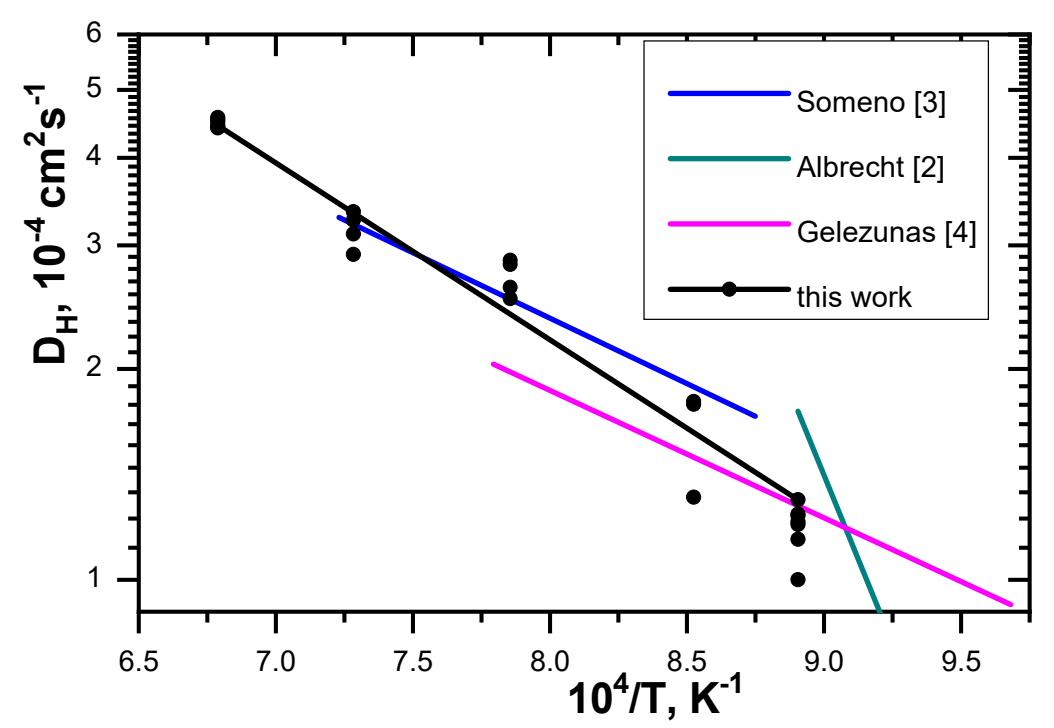

Figure 8. Arrhenius plots of the temperature dependence of the determined diffusivity and temperature correlations given in the literature.

A detailed description of the experiments and the results is given in [11].

\subsection{Hydrogen Uptake during Steam Oxidation in the Temperature Range between 900 and $1400{ }^{\circ} \mathrm{C}$}

The hydrogen uptake of nuclear fuel claddings made of zirconium alloys under accident conditions is of high safety importance. The oxidation of the hot fuel cladding tubes by steam can be described very simply by:

$$
\mathrm{Zr}+2 \mathrm{H}_{2} \mathrm{O}=\mathrm{ZrO}_{2}+4 \mathrm{H}
$$

The produced free hydrogen can recombine with molecular hydrogen $\mathrm{H}_{2}$ or can be absorbed by the remaining metallic zirconium.

$$
4 \mathrm{H}=2(1-\mathrm{f}) \mathrm{H}_{2}+4 \mathrm{f} \mathrm{H}^{\text {absorbed }}
$$

$\mathrm{f}$ is the hydrogen pickup fraction. This so-called secondary hydrogenation during oxidation in steam (it is the hydrogen uptake during the accident, the primary hydrogenation is the uptake during operation) can degrade the toughness of the material if a certain hydrogen concentration is exceeded. This embrittlement increases the risk of fuel rod fragmentation during emergency cooling to terminate the accident. Fuel and fission product release and redistribution would be the consequence.

\subsubsection{Materials and Measurements}

The measurements were performed using $20 \mathrm{~mm}$ long segments of as-received commercial cladding tubes made of Zircaloy-4 (outer diameter, $10.75 \mathrm{~mm}$; wall thickness, $0.725 \mathrm{~mm}$ ) and E110 (Zr-1\% Nb; outer diameter, $9.62 \mathrm{~mm}$; wall thickness, $0.75 \mathrm{~mm})$. The in situ neutron radiography investigations were performed at the ICON facility (SINQ, PSI, Villigen, Switzerland) and at the ANTARES facility (FRM II, TU Munich, Munich, Germany). The measurement parameters are given in Table 1. 
Table 1. Parameters of the in situ neutron radiography measurements.

\begin{tabular}{ccc}
\hline & ICON & ANTARES \\
\hline L/d & 600 & 400 \\
Thermal neutron flux, & $3.9 \times 10^{6}$ & $1.0 \times 10^{8}$ \\
$\mathrm{n} \mathrm{cm}$ c $^{-1}$ & 43 & 97 \\
Pixel size, $\mu \mathrm{m}$ & $44 \mathrm{~mm} \times 44 \mathrm{~mm}$ & $43.7 \mathrm{~mm} \times 43.7 \mathrm{~mm}$ \\
Field of view & 118 & 8.5 \\
Illumination time per frame, $\mathrm{s}$ & 0.0083 & 0.1 \\
Frame repetition frequency, $\mathrm{Hz}$ & & \\
\hline
\end{tabular}

The oxidation tests were performed in a flowing $\mathrm{Ar} /$ steam mixture $(30 \mathrm{~L} / \mathrm{h} \mathrm{Ar}, 30 \mathrm{~g} / \mathrm{h}$ steam) at temperatures between 900 and $1300{ }^{\circ} \mathrm{C}$ in $100 \mathrm{~K}$ steps using the INRRO furnace. The duration of one oxidation test was between 1 and $6 \mathrm{~h}$ depending on the test temperature.

\subsubsection{Data Analysis}

During oxidation by steam, the total macroscopic neutron cross section of the samples changes by the absorption of oxygen, forming an oxide scale at the surface, and by the hydrogen uptake. In order to separate the effect of oxygen and hydrogen, the amount of oxygen bonded or absorbed by the sample was calculated by the known oxidation kinetics. The contribution of the oxygen to the total macroscopic neutron cross section $\Sigma_{O}$ was determined in pretests:

$$
\Sigma_{O}=N_{O} \sigma_{O}=(0.98 \pm 0.04) \mathrm{cm}^{-1} \frac{\Delta m}{m}
$$

$N_{O}$ and $\sigma_{O}$ are the number density and microscopic neutron cross section of oxygen, $\Delta m$ the mass gain after oxidation, and $m$ the initial mass of the sample.

Equation (2) was applied for the subtraction of the contribution of the oxygen to the increase in the total macroscopic neutron cross section of the sample measured in the in situ experiment. The dependence of $\Delta m / m$ on the oxidation time and temperature was determined in former investigations of our own. Figure 9 gives an example of the separation of the effects of oxygen and hydrogen in the total macroscopic neutron crosssection development during oxidation by steam of Zircaloy- 4 at $1200{ }^{\circ} \mathrm{C}$.

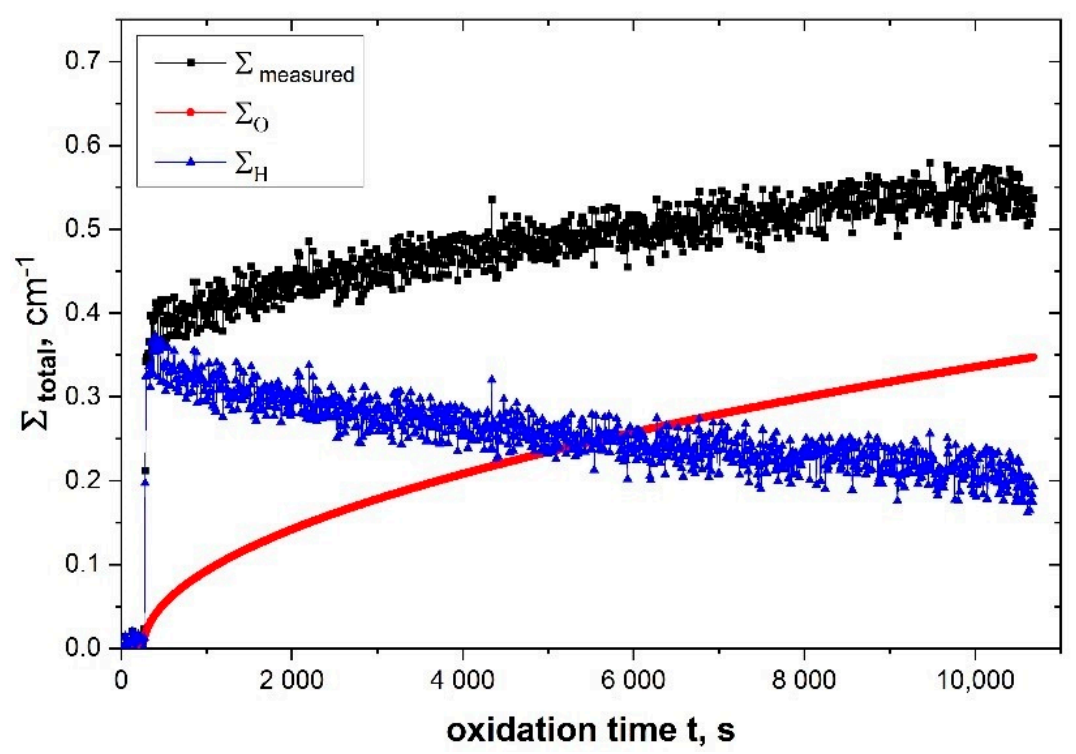

Figure 9. Contributions of oxygen and hydrogen to the increase of the measured total macroscopic neutron cross section of Zry- 4 during steam oxidation at $1200{ }^{\circ} \mathrm{C}$. 


\subsubsection{Results and Discussion}

A neutron radiography video of the reaction of the Zry-4 sample at $1000^{\circ} \mathrm{C}$ in steam is avaible online as the supplement S2. A summary of the hydrogen uptake during the oxidation of Zry-4 cladding tube segments in steam is given in Figure 10. The curve for $900{ }^{\circ} \mathrm{C}$ is not plotted in the diagram. No significant hydrogen uptake was determined during the whole time at this temperature. The reason for this is the monoclinic structure of the zirconium oxide at this temperature, resulting in a much lower oxidation rate, and with it the very low hydrogen partial pressure in the gas phase. At 1100 to $1500{ }^{\circ} \mathrm{C}$, the oxide scale has a tetragonal structure. At $1000{ }^{\circ} \mathrm{C}$, the oxidation starts with a tetragonal structure, which is stabilized by the maximal possible substoichiometry. When the oxygen vacancies are more and more filled, the oxide structure is transferred to the monoclinic one. Due to the differences of the atomic volumes between these two structures, strong stresses are induced by this phase transformation. A pronounced crack structure in the oxide layer is formed at this temperature, known as the breakaway effect.

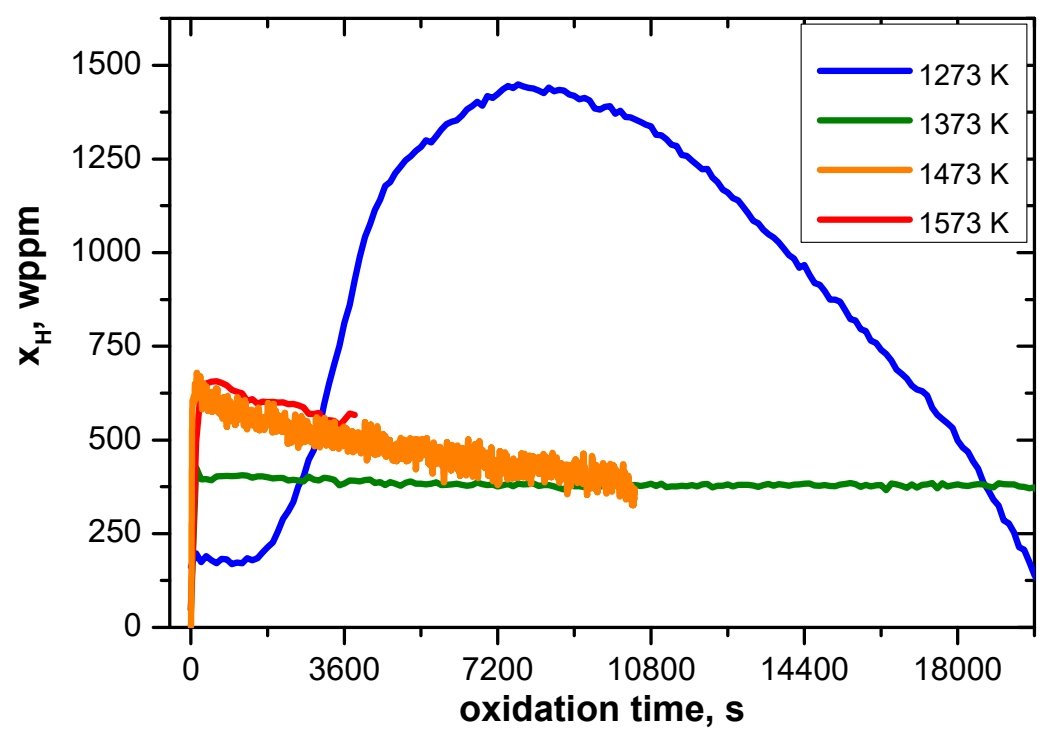

Figure 10. Development of the hydrogen concentration during isothermal oxidation of Zry-4 in steam at temperatures of $1000,1100,1200$, and $1300{ }^{\circ} \mathrm{C}$.

Generally, the initial hydrogen uptake is very fast as long as no protective oxide layer is formed. This finding is new; no other method has provided this information before. This stage of the hydrogen uptake is finished after about $20 \mathrm{~s}$. Later, the hydrogen concentration decreases slightly. The hydrogen absorption increases with increasing temperature. At $1000{ }^{\circ} \mathrm{C}$, the behavior differs after about $30 \mathrm{~min}$. At this time, the crack formation in the oxide scale starts. Open cracks act as a "hydrogen pump": steam penetrates into the cracks and reaches the reaction zone close to the metal/oxide interface. The oxygen is consumed, and the hydrogen remains and becomes enriched in the cracks. The higher hydrogen partial pressure results in an enhanced hydrogen uptake according Sieverts' law. This additional hydrogen absorption has the consequence of a decrease in the total gas pressure in the cracks. New steam is sucked into the cracks to equalize the pressure, and the processes start again. A more detailed description of the tests and results for the E110 alloy and a deeper discussion are given in [18].

\subsection{Investigation of the Reaction of Zry-4 in Steam, Nitrogen/Steam, and Air/Steam Atmospheres}

In the framework of the severe accident research after the Fukushima accidents in 2011, the reaction of the nuclear fuel cladding tubes in steam/nitrogen and steam/air gas mixtures came into focus in research. This is relevant if the emergency cooling water is pressurized by nitrogen or for spent fuel pool accidents. For thermodynamic reasons, zirconium reacts at first with $\mathrm{O}_{2}$ and if oxygen is consumed, and the reaction with steam 
starts. If both oxygen and steam are no longer available, zirconium reacts with nitrogen. If the oxygen and steam starvations are valid for the whole sample, it is called global. If the starvation occurs only at special positions, for instance at the tips of cracks through the oxide scale, it is called local. A model for these reactions was developed, predicting the dependence of the reaction kinetics on the total gas flow: the surprising outcome that the reaction rate is the higher the lower the gas flow is, was experimentally confirmed.

\subsubsection{Measurements}

In order to study details of the reaction kinetics of the oxidation of zirconium alloys in mixed nitrogen-containing atmospheres, in situ neutron radiography investigations were performed at the ANTARES facility at FRM II (TU Munich, Garching, Germany) using the INRRO furnace. The collimation was 1100 in terms of $\mathrm{L} / \mathrm{D}$, and the neutron flux $5.3 \times 10^{7} \mathrm{~cm}^{-2} \mathrm{~s}^{-1}$. The images were taken with a frame repetition rate of $0.033 \mathrm{~Hz}$. A relatively high sample-detector distance of $225 \mathrm{~mm}$ resulted in a lateral resolution of about $250 \mu \mathrm{m}$, which was suitable for the investigations.

The tests were performed at temperatures of $800,900,1000$, and $1100^{\circ} \mathrm{C}$, which is the temperature range of the strongest effect of nitrogen on the reaction kinetics. Cladding tube segments with a length of $20 \mathrm{~mm}$ made of Zircaloy- 4 were oxidized in pure steam as reference in nitrogen/steam atmospheres with constant partial pressures, but with varying total gas flow rates and in an air/steam gas mixture with the same steam partial pressure.

\subsubsection{Data Analysis}

The data analysis was much more complex than in the previous examples because three elements $(\mathrm{H}, \mathrm{O}$, and $\mathrm{N})$ were added to the pristine zircaloy. The amount of these elements changes during reaction with time nonmonotonically because not only oxidation and nitriding but also reoxidation of zirconium nitrides occur when the temporary oxygen or steam starvation is finished. Additionally, a strong swelling of the sample occurs. Under this condition, referencing to the initial sample state is difficult. Therefore, a quantitative analysis of the data was not possible in each case. However, even a qualitative analysis of the data provided new insights in the time scale of changes in the reaction kinetics.

Where possible, the following correlations were applied for a quantitative analysis:

- For hydrogen,

$$
\Delta \Sigma_{\text {total }}^{H}=2.6617 \mathrm{~cm}^{-1} \frac{N^{H}}{N^{Z r}}+0.168 \mathrm{~cm}^{-1}
$$

with $\mathrm{N}$ as the number density of hydrogen and zirconium, respectively.

- For oxygen, the correlation of Equation (2) was used.

- For nitrogen, the contribution to the total neutron cross section $\Delta \Sigma_{\text {total }}^{N}$ was estimated by

$$
\Delta \Sigma_{\text {total }}^{N}=6.0 \mathrm{~cm}^{-2} \overline{\delta_{\mathrm{ZrN}}}
$$

$\overline{\delta_{Z r N}}$ is the mean thickness of the nitride-containing layer. This value can only be determined destructively after the neutron radiography in the sample. Therefore, a parallel sample set was produced for the determination of this parameter.

As already mentioned, the samples changed their shape by swelling. Therefore, two ways of referencing were used: referencing by the initial state of the sample and by the empty furnace at the test temperature.

\subsubsection{Results and Discussion}

A large number of tests were performed. Describing the results of all of them exceeds the framework of this paper. As an example, Figure 11 shows the development of the sample annealed in a nitrogen/steam atmosphere at $900{ }^{\circ} \mathrm{C}$ with a total gas flow rate of $24 \mathrm{~L} / \mathrm{h}$. A neutron radiography video of this reaction is available online as supplement S3. 
The strong swelling is obvious. Macrocracks are visible after a $2 \mathrm{~h}$ reaction. The images are referenced by the image of the empty furnace. The sample holder rod is visible. Referencing with the sample holder rod but without the sample is not successful because the weight of the sample changes the sample holder position slightly but sufficiently that the sample holder appears in the image.

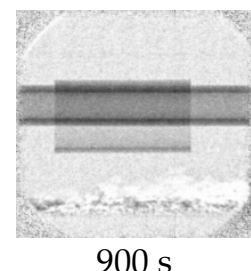

$900 \mathrm{~s}$

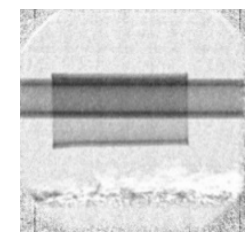

$1800 \mathrm{~s}$

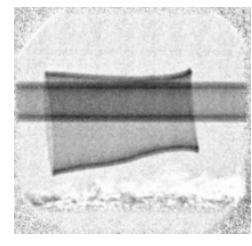

$3600 \mathrm{~s}$

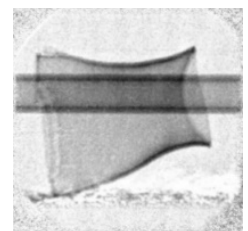

$5580 \mathrm{~s}$

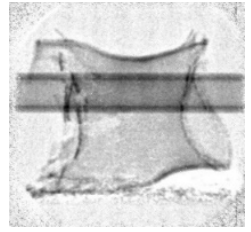

$7200 \mathrm{~s}$

Figure 11. Radiographs of the sample reacted in a nitrogen/steam atmosphere with a total gas flow rate of $24 \mathrm{~L} / \mathrm{h}$.

A comparison of the reaction in the different atmospheres gives information about the influence of nitrogen on the reaction kinetics. In Figure 12, the sample appearances after reaction at $800{ }^{\circ} \mathrm{C}$ for $8 \mathrm{~h}$ and at $1000{ }^{\circ} \mathrm{C}$ for $40 \mathrm{~min}$ are compared for annealing in a pure steam, air/steam, and nitrogen/steam atmosphere, respectively. The samples are referenced by the initial sample state. Due to this referencing, the initial sample image appears brighter if the sample shape is strongly changed like in the image taken after $8 \mathrm{~h}$ reaction in nitrogen/steam.
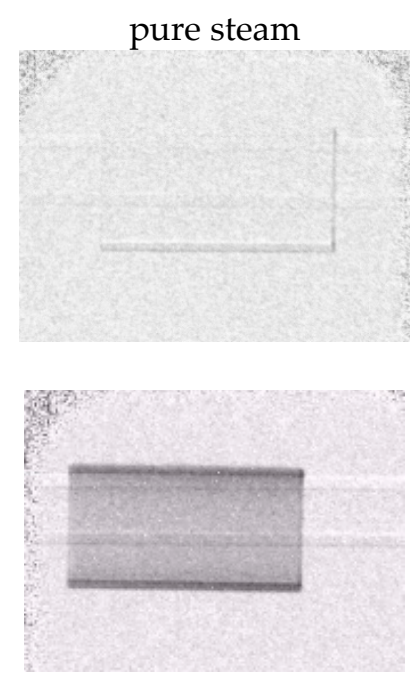

Fure 12. Comparison of neutron radiographs taken after $8 \mathrm{~h}$ reaction at $800{ }^{\circ} \mathrm{C}$ and $40 \mathrm{~min}$ at $1000{ }^{\circ} \mathrm{C}$ in pure steam, air/steam, and nitrogen/steam mixtures (flow rates of $2 \mathrm{~g} / \mathrm{h} \mathrm{H} \mathrm{H}_{2} \mathrm{O}$ and $10 \mathrm{~L} / \mathrm{h}$ nitrogen or oxygen flux, respectively).

Whereas the neutron transmission of the Zry-4 sample does only marginally change after $8 \mathrm{~h}$ reaction at $800{ }^{\circ} \mathrm{C}$ in pure steam, it increases after reaction in an air/steam mixture. In addition, a slight swelling of the sample is visible (former lower edge of the sample appears bright). For the sample annealed in a nitrogen/steam mixture, a strong swelling and a large increase of the total neutron cross section can be observed. The formation of zirconium nitride ( $\mathrm{ZrN}$ ) precipitates in the oxide layer, as well as their reoxidation, is connected to strong volume changes. Similar to the breakaway effect discussed before, many cracks are formed in the oxide scale, resulting in an enhanced hydrogen uptake. In the air/steam mixture, additional oxygen is available, reducing susceptibility to reaction with nitrogen. In addition, less steam is consumed, and with it, less free hydrogen is produced. 
Relations differ for reaction at $1000{ }^{\circ} \mathrm{C}$. The changes in the neutron transmission were lowest after reaction in an air/steam atmosphere. Mainly, the oxygen in the air was consumed, and only little free hydrogen was produced. The increase in the total neutron cross section of the sample oxidized in pure steam was caused by the strong hydrogen uptake due to the breakaway effect discussed before. The strongest reaction was found in the nitrogen/steam atmosphere. Here, the breakaway of the oxide scale started much earlier than in pure steam. It was surprising and unknown before that the first hints of a breakaway of the oxide scale were already detected after a 2 min reaction time. As mentioned before, the breakaway of the oxide scale starts after an approximately $30 \mathrm{~min}$ oxidation time.

More details of the experiments and the results obtained are given in [13] and will be published in [19].

\section{Conclusions and Outlook}

In situ neutron radiography investigations can provide information that cannot be obtained by other methods. The kinetics of chemical reactions can be studied because illumination times of a few seconds are often suitable to obtain relevant data. A high spatial resolution in the range of some hundreds or even tens of micrometers is suitable for studying processes depending on length parameters such as diffusion processes or inhomogeneous reactions influenced by inhomogeneous mechanical stress fields in a sample.

In the framework of the study of hydrogen-related processes in zirconium alloys (hydrogen uptake, diffusion, redistribution), new insights into the kinetics were obtained by in situ neutron radiography experiments. The rapid hydrogen uptake at the beginning of the oxidation of zirconium alloys in steam and the early beginning of the breakaway oxidation in a nitrogen/steam mixed atmosphere are examples.

Recent and near future applications of in situ neutron radiography on the zirconiumhydrogen system are the investigation:

- Of the hydrogen redistribution during the so-called delayed hydride cracking (hydrogen migrates to the stress field ahead of a crack tip, resulting in an embrittlement of this region, the crack growth into this region, and the hydrogen has to migrate to the new position of the stress field until the sample fails);

- Of the redistribution of hydrogen in cladding tubes consisting of two different zirconium alloys (for instance, the $\mathrm{D}_{\mathrm{x}} / \mathrm{D}_{4}$ composite consisting of a Zry-4 bulk and a $150 \mu \mathrm{m}$ thick liner with reduced tin concentration);

- Of parameters influencing the solubility and diffusion rate of hydrogen in cladding tube materials under the conditions of long-term (100 years) dry storage of spent nuclear fuel rods (reorientation of hydrides from a perpendicular to a radial direction under tensile load).

Several groups worldwide work on these fields. The first results have already been achieved (for instance, $[12,20])$. However, all these processes are not yet completely understood and quantified to develop precise models predicting the cladding tube state after long-term storage of nuclear fuel.

Supplementary Materials: The following are available online at https:/ /www.mdpi.com/article/ 10.3390/app11135775/s1: Video S1: Hydrogen diffusion into a Zircaloy-4 solid cylinder, Video S2: Hydrogen uptake during steam oxidation of Zircaloy -4 at $1000^{\circ} \mathrm{C}$, Video S3: Reaction of Zircaloy-4 in a nitrogen/steam atmosphere at $900{ }^{\circ} \mathrm{C}$.

Author Contributions: Conceptualization, M.G.; methodology, M.G., A.K., B.S.; investigation, M.G., A.K., B.S.; writing—original draft preparation, M.G.; writing—review and editing, A.K., B.S. All authors have read and agreed to the published version of the manuscript.

Funding: This research was funded by the program NUSAFE at KIT. No external funding was received.

Institutional Review Board Statement: Not applicable. 
Informed Consent Statement: Not applicable.

Data Availability Statement: The data presented in this study are available on request from the corresponding author.

Acknowledgments: The investigations were performed using the ICON facility at SINQ (PSI Villigen, Switzerland) and the ANTARES facility at FRM II (TU Munich, Garching, Germany). Thanks for providing beamtime and support during the experiments. The authors thank all colleagues from KIT, PSI and TU Munich supporting the investigations. We acknowledge support by the KIT-Publication Fund of the Karlsruhe Institute of Technology.

Conflicts of Interest: The authors declare no conflict of interest.

\section{References}

1. Geelhood, K.; Beyer, C. Hydrogen pickup models for Zircaloy-2, Zircloy-4, M5 ${ }^{\mathrm{TM}}$ AND ZIRLO ${ }^{\mathrm{TM}}$. In Proceedings of the Water Reactor Fuel Performance Meeting, Chengdu, China, 11-14 September 2011.

2. Kearns, J.J. Terminal solubility and partitioning of hydrogen in the alpha phase of zirconium, Zircaloy-2 and Zircaloy-4. J. Nucl. Mater. 1967, 22, 292-303. [CrossRef]

3. Stuckert, J.; Große, M.; Rössger, C.; Klimenkov, M.; Steinbrück, M.; Walter, M. QUENCH-LOCA program at KIT on secondary hydriding and results of the commissioning bundle test QUENCH-L0. Nucl. Engin. Des. 2013, 255, 185-201. [CrossRef]

4. Brachet, J.C.; Hamon, D.; Le Saux, M.; Vandenberghe, V.; Toffolon-Masclet, C.; Rouesne, E.; Urvoy, S.; Bechade, J.-L.; Raepsaet, C.; Lacour, J.-L.; et al. Study of secondary hydriding at high temperature in zirconium based nuclear fuel cladding tubes by coupling information from neutron radiography/tomography, electron probe micro analysis, micro elastic recoil detection analysis and laser induced breakdown spectroscopy microprobe. J. Nucl. Mater. 2017, 488, 267. [CrossRef]

5. Grosse, M.; Lehmann, E.; Vontobel, P.; Steinbrueck, M. Quantitative determination of absorbed hydrogen in oxidised zircaloy by means of neutron radiography. Nucl. Instr. Methods Phys. Res. A 2006, 566, 739. [CrossRef]

6. Agrawal, A.; Kashyap, Y.; Sarkar, P.S.; Behra, A.N.; Shukla, M.; Singh, R.N.; Sinha, A.; Chakravartty, J.K. Study of hydride blisters in Zr-alloy using neutron tomography. J. Nucl. Mater. 2012, 421, 47. [CrossRef]

7. Grosse, M.; Valance, S.; Stuckert, J.; Steinbrueck, M.; Walter, M.; Kaestner, A.; Hartmann, S.; Santisteban, J. Neutron Imaging Investigations of the hydrogen related degradation of the mechanical properties of Zircaloy-4 cladding tubes. MRS Online Proceeding Libr. Arch. 2013, 1528, 705. [CrossRef]

8. Wang, Z.; Garbe, U.; Li, H.; Harrison, R.P.; Kaestner, A.; Lehmann, E. Observations on the Zirconium Hydride Precipitation and Distribution in Zircaloy-4. Metallurg. Mater. Trans. B 2014, 45, 532. [CrossRef]

9. Smith, T.; Bilheux, H.; Ray, H.; Bilheux, J.C.; Yan, Y. High resolution neutron radiography and tomography of hydrided Zircaloy-4 cladding materials. Phys. Proc. 2015, 69, 478. [CrossRef]

10. Tremsin, A.S.; Morgano, M.; Panzner, T.; Lehmann, E.; Filgers, U.; Vallerga, J.V.; McPhate, J.B.; Siegmund, O.H.W.; Feller, W.B. High resolution neutron imaging capabilities at BOA beamline at Paul Scherrer Institut. Nucl. Instrum. Methods Phys. Res. Sect. A Accel. Spectrometers Detect. Assoc. Equip. 2015, 784, 486-493. [CrossRef]

11. Grosse, M.; van den Berg, M.; Goulet, C.; Kaestner, A. In-situ investigation of hydrogen diffusion in Zircaloy-4 by means of neutron radiography. J. Phys. Conf. Ser. 2012, 340, 012106. [CrossRef]

12. Gong, W.; Trtik, P.; Valance, S.; Bertsch, J. Hydrogen diffusion under stress in Zircaloy: High-resolution neutron radiography and finite element modelling. J. Nucl. Mater. 2018, 508, 459. [CrossRef]

13. Grosse, M.; Pulvermacher, S.; Steinbrück, M.; Schillinger, B. In-situ neutron radiography investigations of the reaction of Zircaloy-4 in steam, nitrogen/steam and air/steam atmospheres. Phys. B Condens. Matter 2018, 551, 244-248. [CrossRef]

14. Makowska, M.G.; Theil Kuhn, L.; Cleemann, L.N.; Lauridsen, E.M.; Bilheux, H.Z.; Molaison, J.J.; Santodonato, L.J.; Tremsin, A.S.; Grosse, M.; Morgano, M.; et al. Flexible sample environment for high resolution neutron imaging at high temperatures in controlled atmosphere. Rev. Sci. Instrum. 2015, 86, 125109. [CrossRef] [PubMed]

15. Albrecht, W.M.; Goode, W.D. The Diffusion of Hydrogen in Beta Zirconium; Report No 1373; Battelle Memorial Institute: Columbus, OH, USA, 1960.

16. Simeno, M. Solubility and diffusion of hydrogen in zirconium. Nippon. Kinzoku Gakkaishi 1960, $24,249$.

17. Gelezunas, V.L.; Conn, P.K.; Price, R.H. The diffusion coefficients for hydrogen in $\beta$-zirconium. J. Electr. Soc. 1963, 110, 799. [CrossRef]

18. Grosse, M.; Steinbrueck, M.; Schillinger, B.; Kaestner, A. In Situ Investigations of the Hydrogen Uptake of Zirconium Alloys during Steam Oxidation; ASTM Special Technical Publication: West Conshohocken, PA, USA, 2018; pp. 1114-1135.

19. Grosse, M.; Steinbrück, M.; Pulvermacher, S.; Schillinger, B. Enhanced Hydrogen Uptake and Reaction Kinetics during Oxidation of Zircaloy-4 in Nitrogen-Containing Steam Atmospheres. ASTM STP 1622, in press.

20. Valance, S.; Grosse, M.; Bertsch, J.; Kaestner, A.; Hartmann, S.; Santisteban, J. In situ neutron radiography determination of hydrogen concentration at a stress raiser. In Proceedings of the LWR Fuel Performance Meeting, Charlotte, NC, USA, 15-19 September 2013; pp. 980-985. 